\title{
Effects of aging on B cell function
}

\author{
Daniela Frasca and Bonnie B. Blomberg \\ Department of Microbiology and Immunology, University of Miami Miller School of Medicine, Miami, \\ FL 33101
}

\section{Summary of recent advances}

\begin{abstract}
Ability to make an optimal immune response to vaccines and infectious agents declines with age in humans and animal models. Recent advances have shown intrinsic B cell defects in aged mice and humans, including decreases in Ig class switch recombination (CSR), activation-induced cytidine deaminase (AID), and E47 transcription factor. Effects on somatic hypermutation (SHM) have been varied depending on the system studied. Increase of AID in mice has shown improved CSR but not SHM. The reported microarray analysis of human B cell subsets may now be used to delineate B cell defects with aging and all the advances presented should lead to selecting agents for improved immune response in the elderly.
\end{abstract}

\section{Introduction}

$\mathrm{B}, \mathrm{T}$ and cells of the innate immune system have previously been implicated in a suboptimal immune response in aged humans and mice, but clarity concerning the importance of intrinsic $\mathrm{B}$ cell contributions to this decline and precise molecular biomarkers for B cell deficiencies with age have only recently been elucitated. Herein we review recent contributions in this area as well as others relating to specific B cell deficiencies with age and summarize key classic reports in light of these new findings. The significance of these findings is that they offer specific biological markers to measure the quality of the humoral immune response and as well should lead to protocols to directly improve these and the immune response in the elderly as well as potentially in other immunocompromized individuals.

High affinity antibodies are produced as a consequence of affinity maturation processes which occur in the germinal centers (GC) of B cell follicles [1]. During GC reactions, many activated $\mathrm{B}$ cells undergo apoptosis and only a minority survive and differentiate into centroblasts that undergo clonal expansion in the dark zone of the GC. During proliferation, the process of somatic hypermutation (SHM) introduces base-pair changes into the $\mathrm{V}$ region of the rearranged genes encoding the $\mathrm{IgV}$ of the heavy and light chains. Centroblasts then differentiate into centrocytes and move to the light zone, where the B cell receptor, with the help from T cells and follicular dendritic cells, is selected for improved binding to the antigen. Newly generated centrocytes that produce an unfavourable antibody undergo apoptosis and are removed. A subset of centrocytes undergoes Ig class switch recombination (CSR), a DNA recombination mechanism through which the heavy chain class of the antibody produced by an activated B cell changes from IgM and IgD to either IgG, IgA or IgE. The process occurs within GCs, but also outside of GCs in both T cell-dependent (TD) and T cell-independent (TI) responses [2,

Corresponsing author: Bonnie B. Blomberg, Department of Microbiology and Immunology, University of Miami School of Medicine, P.O. Box 016960 (R-138), Miami, FL 33101, USA, Tel.: 305-243 6040, Fax: 305-243 4623, e-mail: bblomber@ med.miami.edu.

Publisher's Disclaimer: This is a PDF file of an unedited manuscript that has been accepted for publication. As a service to our customers we are providing this early version of the manuscript. The manuscript will undergo copyediting, typesetting, and review of the resulting proof before it is published in its final citable form. Please note that during the production process errors may be discovered which could affect the content, and all legal disclaimers that apply to the journal pertain. 
3]. Antigen-selected centrocytes eventually differentiate into memory B cells which can either differentiate into plasmablasts, or remain as non-secreting precursors for antigen recall [4]. The short-lived plasmablasts migrate to the bone marrow, where they differentiate into longlived plasma cells and provide humoral antibody. Plasmablasts and plasma cells are maintained for long periods of time and compete for space in distict "survival niches" formed by stromal elements [5]. Thus, humoral antibody results from competition between newly generated plasmablasts and plasma cells [5].

\section{Aging decreases humoral responses}

The changes in the humoral immune response with age are both qualitative and quantitative, as affinity, specificity and class of antibody produced are changed. A progressive decline in both the number and the size of GCs has been reported [6], as evaluated by immunohistochemistry and flow cytometry using monoclonal antibodies specific for peanut agglutinin (PNA) and GL-7 [6] or PNA and CD38 [7] (see Table 1). The impairment in GC reactions occurring during aging results from not only $\mathrm{T}$ cell and follicular dendritic cell (FDC) defects but also intrinsic B cell defects, e.g. in decreased SHM of Ig genes. This results in decreased antibody affinity maturation as well as diminished recirculating antibody-secreting plasma cells in the bone marrow [8]. In adoptive transfer experiments, plasma cells producing both low and high affinity antibodies as a consequence of a recent antigenic stimulation were found to be significantly diminished in the bone marrow of old as compared to young mice [9].

The effects of age on antibody affinity maturation are controversial and results obtained by different groups are conflicting. When the IgH V region genes from GC B cell populations were sequenced, SHM was found to be reduced in splenic GCs [10] or increased in Peyer's patch GCs, and especially in IgM, [11] of aged mice, and the reduction was attributed to defective T cell help to B cells in vivo [7]. The reduced SHM could occur by less costimulation (via CD40, CD80, and CD86) or less cytokine stimulation from CD4 T cells. However, when adoptive hosts receiving young $\mathrm{T}$ cells and aged $\mathrm{B}$ cells were tested, they also exhibited a reduced capacity to hypermutate antibody genes, suggesting a deficiency in the B cell compartment as well [12]. CD4 T cells from old mice have been shown to produce less IL-2, proliferate and differentiate poorly upon antigen stimulation [13], and show reduced CD40 ligand expression, crucial for cognate $\mathrm{B} / \mathrm{T}$ interaction [7]. The production of other cytokines is also altered in old age (Th1-derived cytokines are increased and Th2-derived cytokines are decreased) $[14,15]$, thus contributing to reduced vaccine efficacy (as well as increased inflammation).

Studies in humans are also conflicting, showing no change (at least in productive $\mathrm{V}$ genes) in SHM with age in GCs of the spleen but a decrease in GCs of Peyer's patches [16], suggesting that these variations in antibody affinity mainly reflect differences in the way that the antibodies are selected, although perturbations in SHM machinery can also be a possible mechanism. These authors have also more recently shown a decrease in SHM in peripheral blood B cells with age [17*]. In tonsils, the extent of SHM was found unchanged or even increased into the eighth decade of life [18]. These apparent discrepancies may be re-evaluated by considering whether the B cell population being measured is newly challenged with antigen, in which case defects in SHM might be seen with increased age, or whether persistent/increased SHM (e.g. in the tonsil) may reflect accumulation of SHM upon repeated antigenic stimulation.

\section{Specific antibody responses are impaired in aged mice and humans}

Aging in mice is associated with a decreased production of precursor $B$ cells in the bone marrow [19-21], which also likely reflects decrease in precursor/stem cells with age $[22,23]$. However, the population of mature splenic B cells is maintained, in part, in aged mice because of their 
increased life-span [24*]. This seems to occur because the peripheral pool is filled with B cells that are long-lived at least in part as a consequence of specificity for, and chronic stimulation by, environmental antigens [25], and also because the number of B cells secreting antibodies to autoantigens increases with age [26]. In contrast with mouse B cells, human peripheral B cell percentages and numbers significantly decrease with age [27-29**]. There is one other report [30] and a review [31] showing that memory B cell percentages increase not significantly with age, but the majority favor a decrease.

The absolute numbers of human $\mathrm{B}$ cell precursors in the bone marrow have been shown to decline [32] or not decline [33] with age. The percentage of peripheral blood naïve B cells is increased and their absolute numbers remain unchanged in old individuals [28,29**]. Both human naïve and IgM memory B cells show defects in CSR [29**]. Therefore switch memory cells are deficient in number and function (for CSR), whereas naïve cells are deficient only functionally. Similarly, in the human tonsil, naive B cells have been shown to increase with age [18]. The percentage of IgM memory B cells are not significantly decreased but the absolute numbers are (a result of decreased total B cells with age) [29**]. The reduction in IgM cells has been suggested to cause reduced specific antibody titers in elderly individuals vaccinated against pneumococcal polysaccharides and to Streptococcus pneumoniae infection [28]. The reduction in TI responses with age is less severe than that of TD responses and mimics the same differences seen in mice $[28,34]$ and below). Very recent molecular characterization of B cell subsets by the Tangye laboratory [35*] should allow better analysis of human B cell deficits with age in the future.

The antibodies generated in old mice are less protective compared to the antibodies generated in young mice [36]. Age-associated alterations in B cell repertoire expression have also been reported, old mice showing a shift in antibody repertoire from non-self to self-recognition and from high to low affinities [37,38]. A skewing of V-gene usage has also been reported [39]. In old mice the immune response to influenza has less $\mathrm{IgG}$ than that in young mice. It was shown that young mice had mostly IgG1 plasma cells producing high affinity antibody after immunization, whereas aged mice had predominantly IgM plasma cells [9]. The total number of anti-dinitrophenyl (DNP) plaque-forming cells generated in the spleen of old mice immunized with the TD antigen DNP-bovine gamma globulin, have been reported to be only $15 \%$ of that observed in young mice [40], whereas old mice immunized with the TI antigen DNP-Ficoll were able to make as many plaque-forming cells as young mice did, confirming results obtained with other TI antigens, such as type III pneumococcal polysaccharide (SIII) and LPS [41].

Although antigen-specific antibody responses decline in old mice, total levels of serum antibodies are increased in mice [42] and humans [29**,43]. These results may be explained as the initial antigenic stimulation is defective in aged B cells. The accumulation in the sera of IgG may come from plasmablasts secreting antibodies of suboptimal quality both in affinity and polyclonality, or from normal or increased numbers of Ig-secreting cells present in lymphoid organs, including mucosal tissues. We cannot yet exclude differences in B cell homing and recirculation processes with age, but others have also shown defects in Peyer's patch B cell function, SHM [16] and CSR [11], with age.

\section{Molecular mechanisms for the reduced activity of B cells in aged mice and humans}

The inability of B cells from old individuals to respond to vaccination is due to a defect in the molecular events leading to the production of secondary isotypes by CSR. In this process, activation-induced cytidine deaminase (AID) is required [44,45]. AID initiates CSR by deamination of cytidine residues in $\mathrm{S}$ regions, thus creating uracils, and the resulting 
mismatches are recognized by specific enzymes and excised, leading to DNA double strand breaks [44,46]. AID is also necessary for SHM [44,45]. E2A activity is necessary for CSR because the $\mathrm{E} 47$ transcription factor has been shown to be important in transcriptional regulation of Aicda, the gene encoding AID [47,48].

We have previously shown that in vitro stimulated splenic B cells from old mice are deficient in the production of multiple class switch isotypes and CSR [49]. Our preliminary data indicate that stimulated follicular naïve splenic B cells are impaired in aged mice for CSR. This occurs concomitant with decreased induction of E47 and AID. Others have shown no difference between young and old B cells in AID levels [50], but this could be due to a different time of measuring AID ( $48 \mathrm{~h}$ versus $4-5$ days in our study) [49]. Although B cells may suffer from a lack of adequate $\mathrm{T}$ cell help in aging, as we have discussed above, we have demonstrated that intrinsic changes in B cells also occur and have a significant impact on antibody production. The mechanism for the age-related decrease in E47 levels in old splenic B cells is mRNA stability [51] (see model, Fig. 1). E47 protein degradation rates are comparable in young versus aged B cells, in contrast with bone marrow-derived IL-7-expanded pro-B/early pre-B cells [52]. The stability of E47 mRNA is regulated at least in part by the p38 MAPK signal transduction cascade, which phosphorylates a protein, tristetraprolin (TTP), that interacts with the adenylate/uridylate-rich elements (ARE) in the 3' untranslated region (UTR) of many mRNAs modifying their stability [53*]. We have found that tristetraprolin (TTP), a physiological regulator of mRNA expression and stability, is involved in the degradation of the E47 mRNA [54**]. TTP mRNA and protein levels are higher in stimulated splenic B cells from old mice as compared with young mice. Inhibition of the p38 MAPK signaling pathway significantly reduces TTP protein phosphorylation in B cells. Old B cells in response to LPS make less phosphorylated p38 MAPK [54**] and therefore, as would be expected, make less phosphorylated TTP. This leads to an increase in the amount of TTP bound to the 3'-UTRs of E47 (and inflammatory cytokines, e.g. TNF- $\alpha$ ) and therefore decreased E47 mRNA stability in old B cells. We hypothesize that the increase in inflammatory cytokines [15] seen in aging feeds back to increase degradation of inflammatory cytokine mRNAs in aged B cells and as a side effect E47 and B cell function is decreased in aged mice and humans. Our preliminary data show that TNF- $\alpha$-stimulated splenic B cells from old mice are impaired in their ability to induce AID and CSR to IgA.

We have recently extended our studies on murine B cells to human B cells to investigate whether aging also affects CSR, E47 and AID expression in B cells isolated from the peripheral blood of human subjects. Elderly humans have fewer percentages of CD19+ total B cells, switch memory B cells, and increased percentages of naïve B cells. They also have less E47, AID and Ig $\gamma 1$ circle transcripts [29**].

As AID had previously been shown to be necessary for both CSR and SHM, we would have predicted defects in both of these with aging. We have directly shown defects in CSR in mice and human subjects. Data from others on SHM in aging are less clear as discussed above but this may also reflect more dependence of CSR, as compared with SHM, on AID levels, as the Nussenzweig and Papavasiliou laboratories have recently shown increase of AID in mouse models elevates CSR but SHM is not changed [55*,56*].

\section{Conclusions}

Results in mice and humans provide a possible molecular mechanism for a B cell intrinsic defect in the humoral immune response with aging. Although there are defects in $\mathrm{T}$ cells as well as in B cells during aging, these results suggest that improving the aged immune response will likely require methods to directly improve the function of B cells as well as T cells in elderly individuals. 


\section{Acknowledgments}

This work is supported by NIH AG-23717 and AG28586 (BBB).

\section{References and recommended reading}

1. Klein U, Dalla-Favera R. Germinal centres: role in B-cell physiology and malignancy. Nat Rev Immunol 2008;8:22-33. [PubMed: 18097447]

2. Cerutti A. The regulation of IgA class switching. Nat Rev Immunol 2008;8:421-434. [PubMed: 18483500]

3. Garcia de Vinuesa C, O’Leary P, Sze DM, Toellner KM, MacLennan IC. T-independent type 2 antigens induce B cell proliferation in multiple splenic sites, but exponential growth is confined to extrafollicular foci. Eur J Immunol 1999;29:1314-1323. [PubMed: 10229099]

4. McHeyzer-Williams MG. B cells as effectors. Curr Opin Immunol 2003;15:354-361. [PubMed: 12787764]

5. Tarlinton D, Radbruch A, Hiepe F, Dorner T. Plasma cell differentiation and survival. Curr Opin Immunol 2008;20:162-169. [PubMed: 18456483]

6. Zheng B, Han S, Takahashi Y, Kelsoe G. Immunosenescence and germinal center reaction. Immunol Rev 1997;160:63-77. [PubMed: 9476666]

7. Eaton SM, Burns EM, Kusser K, Randall TD, Haynes L. Age-related defects in CD4 T cell cognate helper function lead to reductions in humoral responses. J Exp Med 2004;200:1613-1622. [PubMed: 15611289]

8. Manz RA, Thiel A, Radbruch A. Lifetime of plasma cells in the bone marrow. Nature 1997;388:133134. [PubMed: 9217150]

9. Han S, Yang K, Ozen Z, Peng W, Marinova E, Kelsoe G, Zheng B. Enhanced differentiation of splenic plasma cells but diminished long-lived high-affinity bone marrow plasma cells in aged mice. $\mathrm{J}$ Immunol 2003;170:1267-1273. [PubMed: 12538685]

10. Miller C, Kelsoe G. Ig VH hypermutation is absent in the germinal centers of aged mice. J Immunol 1995;155:3377-3384. [PubMed: 7561032]

11. Rogerson BJ, Harris DP, Swain SL, Burgess DO. Germinal center B cells in Peyer's patches of aged mice exhibit a normal activation phenotype and highly mutated IgM genes. Mech Ageing Dev 2003;124:155-165. [PubMed: 12633935]

12. Yang X, Stedra J, Cerny J. Relative contribution of T and B cells to hypermutation and selection of the antibody repertoire in germinal centers of aged mice. J Exp Med 1996;183:959-970. [PubMed: 8642299]

13. Haynes L, Linton PJ, Eaton SM, Tonkonogy SL, Swain SL. Interleukin 2, but not other common gamma chain-binding cytokines, can reverse the defect in generation of CD4 effector T cells from naive T cells of aged mice. J Exp Med 1999;190:1013-1024. [PubMed: 10510091]

14. Engwerda CR, Fox BS, Handwerger BS. Cytokine production by T lymphocytes from young and aged mice. J Immunol 1996;156:3621-3630. [PubMed: 8621895]

15. Pawelec G, Barnett Y, Forsey R, Frasca D, Globerson A, McLeod J, Caruso C, Franceschi C, Fulop T, Gupta S, et al. T cells and aging, January 2002 update. Front Biosci 2002;7:d1056-1183. [PubMed: 11991846]

16. Banerjee M, Mehr R, Belelovsky A, Spencer J, Dunn-Walters DK. Age- and tissue-specific differences in human germinal center B cell selection revealed by analysis of IgVH gene hypermutation and lineage trees. Eur J Immunol 2002;32:1947-1957. [PubMed: 12115615]

17. Gibson KL, Wu YC, Barnett Y, Duggan O, Vaughan R, Kondeatis E, Nilsson BO, Wikby A, Kipling $\mathrm{D}$, Dunn-Walters DK. * B-cell diversity decreases in old age and is correlated with poor health status. Aging Cell 2009;8:18-25. B cell repertoire as measured by spectratyping and DNA sequencing in individuals aged 86-94 showed less Ig diversity than young especially in the more frail group. [PubMed: 18986373]

18. Kolar GR, Mehta D, Wilson PC, Capra JD. Diversity of the Ig repertoire is maintained with age in spite of reduced germinal centre cells in human tonsil lymphoid tissue. Scand J Immunol 2006;64:314-324. [PubMed: 16918701] 
19. Sherwood EM, Blomberg BB, Xu W, Warner CA, Riley RL. Senescent BALB/c mice exhibit decreased expression of lambda5 surrogate light chains and reduced development within the pre-B cell compartment. J Immunol 1998;161:4472-4475. [PubMed: 9794368]

20. Miller JP, Allman D. The decline in B lymphopoiesis in aged mice reflects loss of very early B-lineage precursors. J Immunol 2003;171:2326-2330. [PubMed: 12928378]

21. Alter-Wolf S, Blomberg BB, Riley RL. Deviation of the B cell pathway in senescent mice is associated with reduced surrogate light chain expression and altered immature B cell generation, phenotype, and light chain expression. J Immunol 2009;182:138-147. [PubMed: 19109144]

22. Min H, Montecino-Rodriguez E, Dorshkind K. Effects of aging on the common lymphoid progenitor to pro-B cell transition. J Immunol 2006;176:1007-1012. [PubMed: 16393987]

23. Guerrettaz LM, Johnson SA, Cambier JC. Acquired hematopoietic stem cell defects determine B-cell repertoire changes associated with aging. Proc Natl Acad Sci U S A 2008;105:11898-11902. [PubMed: 18697924]

24. Miller JP, Cancro MP. * B cells and aging: balancing the homeostatic equation. Exp Gerontol 2007;42:396-399. B cells from aged mice survive better in response to BlyS, helping to explain the maintenance of peripheral B cells although being derived from fewer precursors. [PubMed: 17344004]

25. Johnson SA, Rozzo SJ, Cambier JC. Aging-dependent exclusion of antigen-inexperienced cells from the peripheral B cell repertoire. J Immunol 2002;168:5014-5023. [PubMed: 11994453]

26. Weksler ME. Changes in the B-cell repertoire with age. Vaccine 2000;18:1624-1628. [PubMed: 10689139]

27. Franceschi C, Monti D, Sansoni P, Cossarizza A. The immunology of exceptional individuals: the lesson of centenarians. Immunol Today 1995;16:12-16. [PubMed: 7880382]

28. Shi Y, Yamazaki T, Okubo Y, Uehara Y, Sugane K, Agematsu K. Regulation of aged humoral immune defense against pneumococcal bacteria by IgM memory B cell. J Immunol 2005;175:3262-3267. [PubMed: 16116217]

29. Frasca D, Landin AM, Lechner SC, Ryan JG, Schwartz R, Riley RL, Blomberg BB. ** Aging downregulates the transcription factor $\mathrm{E} 2 \mathrm{~A}$, activation-induced cytidine deaminase, and Ig class switch in human B cells. J Immunol 2008;180:5283-5290. Aged human B cells have less total B cells, less class switch memory B cells, and show less E47, AID, and CSR when stimulated in vitro with antiCD40 plus IL-4. [PubMed: 18390709]

30. Colonna-Romano G, Bulati M, Aquino A, Scialabba G, Candore G, Lio D, Motta M, Malaguarnera M, Caruso C. B cells in the aged: CD27, CD5, and CD40 expression. Mech Ageing Dev 2003;124:389-393. [PubMed: 12714244]

31. Siegrist CA, Aspinall R. B-cell responses to vaccination at the extremes of age. Nat Rev Immunol 2009;9:185-194. [PubMed: 19240757]

32. McKenna RW, Washington LT, Aquino DB, Picker LJ, Kroft SH. Immunophenotypic analysis of hematogones (B-lymphocyte precursors) in 662 consecutive bone marrow specimens by 4-color flow cytometry. Blood 2001;98:2498-2507. [PubMed: 11588048]

33. Rossi MI, Yokota T, Medina KL, Garrett KP, Comp PC, Schipul AH Jr, Kincade PW. B lymphopoiesis is active throughout human life, but there are developmental age-related changes. Blood 2003;101:576-584. [PubMed: 12393702]

34. Frasca D, Riley RL, Blomberg BB. Aging murine B cells have decreased class switch induced by anti-CD40 or BAFF. Exp Gerontol 2007;42:192-203. [PubMed: 17067770]

35. Good KL, Avery DT, Tangye SG. * Resting human memory B cells are intrinsically programmed for enhanced survival and responsiveness to diverse stimuli compared to naive B cells. J Immunol 2009;182:890-901. Human B cell subsets analyzed by microarray show different phenotypes for activation, costimulation and survival markers. [PubMed: 19124732]

36. Nicoletti C, Yang X, Cerny J. Repertoire diversity of antibody response to bacterial antigens in aged mice. III. Phosphorylcholine antibody from young and aged mice differ in structure and protective activity against infection with Streptococcus pneumoniae. J Immunol 1993;150:543-549. [PubMed: 8419487]

37. Nicoletti C, Borghesi-Nicoletti C, Yang XH, Schulze DH, Cerny J. Repertoire diversity of antibody response to bacterial antigens in aged mice. II. Phosphorylcholine-antibody in young and aged mice 
differ in both VH/VL gene repertoire and in specificity. J Immunol 1991;147:2750-2755. [PubMed: 1918989]

38. Yang X, Stedra J, Cerny J. Repertoire diversity of antibody response to bacterial antigens in aged mice. IV. Study of VH and VL gene utilization in splenic antibody foci by in situ hybridization. J Immunol 1994;152:2214-2221. [PubMed: 8133035]

39. Ben-Yehuda A, Szabo P, LeMaoult J, Manavalan JS, Weksler ME. Increased VH 11 and VH Q52 gene use by splenic B cells in old mice associated with oligoclonal expansions of CD5 + B cells. Mech Ageing Dev 1998;103:111-121. [PubMed: 9701765]

40. Goidl EA, Innes JB, Weksler ME. Immunological studies of aging. II. Loss of IgG and high avidity plaque-forming cells and increased suppressor cell activity in aging mice. J Exp Med 1976;144:10371048. [PubMed: 62009]

41. Smith AM. The effects of age on the immune response to type III pneumococcal polysaccharide (SIII) and bacterial lipopolysaccharide (LPS) in BALB/c, SJL/J, and C3H mice. J Immunol 1976;116:469474. [PubMed: 2635]

42. Speziali E, Santiago AF, Fernandes RM, Vaz NM, Menezes JS, Faria AM. Specific immune responses but not basal functions of B and T cells are impaired in aged mice. Cell Immunol 2009;256:1-5. [PubMed: 19233350]

43. Paganelli R, Quinti I, Fagiolo U, Cossarizza A, Ortolani C, Guerra E, Sansoni P, Pucillo LP, Scala E, Cozzi E, et al. Changes in circulating B cells and immunoglobulin classes and subclasses in a healthy aged population. Clin Exp Immunol 1992;90:351-354. [PubMed: 1424294]

44. Muramatsu M, Nagaoka H, Shinkura R, Begum NA, Honjo T. Discovery of activation-induced cytidine deaminase, the engraver of antibody memory. Adv Immunol 2007;94:1-36. [PubMed: 17560270]

45. Nussenzweig MC, Alt FW. Antibody diversity: one enzyme to rule them all. Nat Med 2004;10:13041305. [PubMed: 15580255]

46. Rada C, Williams GT, Nilsen H, Barnes DE, Lindahl T, Neuberger MS. Immunoglobulin isotype switching is inhibited and somatic hypermutation perturbed in UNG-deficient mice. Curr Biol 2002;12:1748-1755. [PubMed: 12401169]

47. Quong MW, Romanow WJ, Murre C. E protein function in lymphocyte development. Annu Rev Immunol 2002;20:301-322. [PubMed: 11861605]

48. Sayegh CE, Quong MW, Agata Y, Murre C. E-proteins directly regulate expression of activationinduced deaminase in mature B cells. Nat Immunol 2003;4:586-593. [PubMed: 12717431]

49. Frasca D, Van der Put E, Riley RL, Blomberg BB. Reduced Ig class switch in aged mice correlates with decreased E47 and activation-induced cytidine deaminase. J Immunol 2004;172:2155-2162. [PubMed: 14764681]

50. Han S, Marinova E, Zheng B. Rectification of age-related impairment in Ig gene hypermutation during a memory response. Int Immunol 2004;16:525-532. [PubMed: 15039382]

51. Frasca D, Van der Put E, Landin AM, Gong D, Riley RL, Blomberg BB. RNA stability of the E2Aencoded transcription factor E47 is lower in splenic activated B cells from aged mice. J Immunol 2005;175:6633-6644. [PubMed: 16272318]

52. Van der Put E, Frasca D, King AM, Blomberg BB, Riley RL. Decreased E47 in senescent B cell precursors is stage specific and regulated posttranslationally by protein turnover. J Immunol 2004;173:818-827. [PubMed: 15240668]

53. Stoecklin G, Anderson P. * Posttranscriptional mechanisms regulating the inflammatory response. Adv Immunol 2006;89:1-37. This review discusses the factors that regulate the stability of the mRNAs for pro-inflammatory cytokines especially TNF. [PubMed: 16682271]

54. Frasca D, Landin AM, Alvarez JP, Blackshear PJ, Riley RL, Blomberg BB. ** Tristetraprolin, a negative regulator of mRNA stability, is increased in old B cells and is involved in the degradation of E47 mRNA. J Immunol 2007;179:918-927. This paper describes for the first time that the mRNA for E47 is a target for the degradation protein TTP. [PubMed: 17617583]

55. Dorsett Y, McBride KM, Jankovic M, Gazumyan A, Thai TH, Robbiani DF, Di Virgilio M, SanMartin BR, Heidkamp G, Schwickert TA, et al. * MicroRNA-155 suppresses activation-induced cytidine deaminase-mediated Myc-Igh translocation. Immunity 2008;28:630-638. The authors show 
that increased levels of AID result in a small increase of CSR but no effect on SHM, although Myc oncogene-IgH translocation is increased by AID. [PubMed: 18455451]

56. Teng G, Hakimpour P, Landgraf P, Rice A, Tuschl T, Casellas R, Papavasiliou FN. * MicroRNA-155 is a negative regulator of activation-induced cytidine deaminase. Immunity 2008;28:521-529. This paper demonstrates that miR-155 is upregulated in murine B cells undergoing CSR and it targets AID degradation. These and the previous authors [55] showed that disruption of the miR-155 target site in the AID 3'UTR increased AID and CSR but SHM was unchanged. [PubMed: 18387832] 


\section{Young B cells}

\section{p-p38 MAPK $\rightarrow$ p-TTP $\rightarrow$ $\rightarrow$ E47 mRNAstability $\rightarrow \uparrow E 47 \rightarrow \uparrow$ AID $\rightarrow \uparrow$ CSR $\rightarrow$ IgG}

\section{Aged B cells}

\section{$\downarrow$ P-p38 MAPK $\rightarrow \downarrow$ p-TTP $\rightarrow \downarrow$ E47 mRNAstability $\rightarrow \downarrow$ E47 $\rightarrow \downarrow$ AID $\rightarrow \downarrow$ CSR $\rightarrow \downarrow$ IgG (†TTP)}

Fig. 1. Mechanism for decreased CSR in aged activated $B$ cells The details of this model have been determined in activated B cells from mice [34,49,51,54], but human activated B cells also share the components following and including E47 mRNA stability [29]. Activated B cells from old subjects have less IgG, CSR, AID and E47 than those from young subjects. The molecular mechanism for this is that E47 mRNA stability is lower in B cells from older mice/humans and in mice this reflects more TTP and less phosphorylated TTP in old cells binding to the 3'UTR of E47 mRNA and causing its degradation. Less phosphop38 MAPK generates this pathway in old B cells. 
Table 1

Age-related changes in B cells in mice and humans

\begin{tabular}{|c|c|c|}
\hline Parameter & Mice (> 18 months) & Humans ( $>65$ years) \\
\hline \multirow[t]{2}{*}{ Bone marrow B cell progenitors } & decreased [19-21] & decreased [32] \\
\hline & & unchanged [33] \\
\hline B cell numbers & unchanged [24] & reduced [27-29] \\
\hline $\begin{array}{l}\text { Peripheral blood naïve B cells } \\
\text { (CD19+IgD+CD27-) } \\
\text { Peripheral blood naïve B cells } \\
(\mathrm{CD} 19+\mathrm{CD} 27-\operatorname{IgG}-\mathrm{IgA}-)\end{array}$ & nd & $\begin{array}{l}\text { increased } \% \text { and unchanged number [28] } \\
\text { increased } \% \text { and unchanged number [29] }\end{array}$ \\
\hline $\begin{array}{l}\text { Tonsil naïve B cells (IgD+CD38 } \\
- \text {-CD27-) }\end{array}$ & nd & increased \% [18] \\
\hline $\begin{array}{l}\text { Peripheral blood total memory B } \\
\text { cells }(\mathrm{CD} 19+\mathrm{CD} 27+)\end{array}$ & nd & increased \% (not significantly) [30] \\
\hline $\begin{array}{l}\text { Peripheral blood IgM memory B } \\
\text { cells }(\mathrm{CD} 19+\mathrm{IgD}+\mathrm{CD} 27+)\end{array}$ & nd & unchanged $\%$ and decreased number [28] \\
\hline $\begin{array}{l}\text { Peripheral blood IgM memory B } \\
\text { cells (CD19+CD27+IgG-IgA-) }\end{array}$ & nd & unchanged $\%$ and decreased number [29] \\
\hline $\begin{array}{l}\text { Peripheral blood switch memory } \\
\text { B cells (CD19+IgG+IgA+) }\end{array}$ & nd & Decreased $\%$ and number [29] \\
\hline GCs & decreased in number and size $[6,7]$ & decreased $\%$ of $\operatorname{IgD}-\mathrm{CD} 38+\mathrm{CD} 27-\mathrm{B}$ cells in tonsil [18] \\
\hline CSR & decreased $[34,49]$ & decreased $[28,29]$ \\
\hline SHM & $\begin{array}{l}\text { reduced in splenic GCs [10] } \\
\text { increased for IgM in Peyer's patch GCs [11] }\end{array}$ & $\begin{array}{c}\text { unchanged in splenic GCs [16] } \\
\text { decreased in Peyer's patch GCs [16] } \\
\text { decreased in peripheral B cells [17] } \\
\text { unchanged or increased in tonsil [18] }\end{array}$ \\
\hline In vitro $\operatorname{IgG}$ & decreased $[34,49]$ & decreased [29] \\
\hline Serum IgG & increased [42] & increased [29] \\
\hline Serum IgM,G,A & & increased [43] \\
\hline Plasma cells & $\begin{array}{l}\text { decreased after immunization with TD antigens } \\
{[40]} \\
\text { unchanged after immunization with TI antigens } \\
{[41]}\end{array}$ & nd \\
\hline
\end{tabular}

nd, not done; CSR, class switch recombination; GCs, germinal centers; SHM, somatic hypermutation 